\title{
Versatile Applications of Different Septal Correction Techniques in Rhinoplasty
}

\author{
AHMED ABDEL FATTAH EL SHERIFA, M.Sc.; MOHAMMED HASSAN EL FAHAR, M.D.; \\ MOHAMED RADWAN EL-HADIDY, M.D.; AHMED MOHAMMED BAHAA ELDIN, M.D. and \\ TAREK AHMED ZAHRA, M.D.
}

The Department of Plastic Surgery, Faculty of Medicine, Mansoura University

\begin{abstract}
Nasal obstruction due to septal deviation is a common problem. In addition to the functional problem it may cause an aesthetic deformity. Several septal correction techniques have been evolved over the years either through open or the endoscopic approaches. Beside the classic Insitu septal correction techniques; extracorporeal septoplasty represents an effective tool in the management of severely deviated septum. The internal nasal valves are the narrowest part of the upper airway system. Their reconstruction is very essential step for a successful functional outcome. In the current study, the authors compared between two groups of patients. The first group was the extracorporeal septoplasty and the second group was the Insitu septoplasty. In both groups; they used spreader grafts for the internal valve reconstruction. The procedure then was conducted with the same essential steps of rhinoplasty according to each case individually. A validated subjective score for functional assessment of the improvement (NOSE) was used. NOSE score was used for subjective assessment of the results before and 6 months after the procedure. Statistically, results were nearly the same between the two groups after 6 months. The authors concluded that both techniques were effective in the management of moderate to severe septal deviation provided that the internal valve was constructed with spreader grafts.
\end{abstract}

Key Words: Extracorporeal - Spreader grafts - Insitu Septoplasty.

\section{INTRODUCTION}

The main aim of rhinoplasty is to create an attractive and functional nose without any surgical stigmata. However, this target can be only performed if the surgeon understands the direct relations between surface aesthetics, underlying anatomical features, and functional factors [1]. It is considered one of the most frequently conducted techniques in plastic surgery, with 213.780 procedures done in United States alone in 2018 [2].

The nasal septum has an essential role in the function as well as the shape of the nose. Septum deformities might induce breathing difficulties, sleeping problems, chronic upper and lower respiratory tract infections, and hypersensitivity disorders, which can affect the patient life. In addition, they may induce curvatures in the nasal axis, with a subsequent development of aesthetic imperfections [3].

Septal deviation is a frequent etiology of nasal obstruction, present in up to $80 \%$ of the overall population [4]. In cases with deviated noses, septal correction is important for treatment success [5]. Septoplasty is one of the most frequent techniques conducted by rhinoplasty surgeons. The aim of septoplasty is to create a straight septum to alleviate anatomic nasal obstruction [6].

Various modalities were described over the last several years with an ongoing debate as regards indications, surgical procedures and possibilities of septum destabilization and perforation [7].

Several septoplasty procedures, including bony batten grafting, septal extension grafting, and cutting and suture procedures, were established to treat the aesthetic and functional forms of deviated noses especially in severe cases. These Insitu septal corrections (ISSCs) are very successful procedures for correction of the nasal septum and external nose in cases with deviated noses $[\mathbf{8 , 9 ]}$.

These (ISSCs) remain of a questionable effect as regard the management of severely deviated septum. Extracorporeal septoplasty for septal curvatures that cannot be straightened via classical septoplasty procedures was defined by King and Ashley in 1950s [10] and was popularized clinically by Gubisch [11].

This procedure involves removal of the quadrilateral cartilage, correction of its shape and place- 
ment of the reshaped cartilage. From that time to the current day, functional as well as aesthetic results of this technique have been assessed accurately and the procedure has been revised for the goals of improving and standardizing the technique particularly the cases of cleft lip deformities and nasal trauma $[\mathbf{1 2 , 1 3 ]}$.

Severe septal deviation causes disturbance in the nasal valve area. The nasal valve area has a main role in nasal breathing. Physiological studies demonstrate that this complex region significantly regulates both nasal airflow and nasal resistance [14].

Some of the potential causes of persistent obstruction are the misidentification or insufficient management of the internal nasal valve collapse [15].

Nowadays, multiple surgical procedures are utilized to support the nasal valve area, as described by Fischer and Gubisch including; anterior septoplasty, septal extension grafts, splay g1aft, suture procedures, and spreader grafts [16]. Spreader grafting offers support for the internal nasal valve. The actual benefit of such technique is to protect the continuity of the upper lateral cartilages and septum, thus guaranteeing increased tension to open the valve angle [17].

Our hypothesis in this study was that classic Insitu septal correction techniques plus spreader graft can produce near the same functional and aesthetic outcome of extracorporeal septorhinoplasty.

We aimed in this study to assess the versatility of various septal correction techniques on the functional and aesthetic outcomes of septorhinoplasty.

\section{PATIENTS AND METHODS}

This study was conducted on 30 patients over 24 months between 2017 and 2019 at the Burn, Plastic \& Reconstructive Surgery Department, Mansoura University. It was a prospective comparative randomized study. Closed envelop method was used for randomization into two groups each one consisted of 15 patients. The first group was extracorporeal septoplasty (ECS) and the second one was the Insitu septoplasty group (ISS).

This study was approved by medical research ethics committee Faculty of Medicine, Mansoura University, Egypt with code no: 16.12.12 on $12 / 12 / 2016$. An informed written consent was obtained from each participant in the study after assuring confidentiality. The study included all adult patients above 16 years old who were seeking septorhinoplasty with any manifestations of moderate to severe nasal septum deviation. It excluded our all the patients with body dysmorphic disorder.

All cases underwent detailed history taking and examination before the procedure to detect the severity of the obstructive symptoms and signs. We used nasal obstruction score evaluation (NOSE) score as a basal reference to detect the improvement after six months. Senior resident with no conflict of interest conducted the basal scoring.

\section{NOSE scale:}

NOSE scale is a questionnaire that subjectively assesses obstructive nasal symptoms. It was created by Stewart who revealed its validity via a prospective observational multicenter research [18].

It considers 5 parameters: Nasal congestion, nasal obstruction, respiratory difficulties, sleep disturbances, and respiratory disturbances under physical exercise. The scale ranges from 0 , in which the parameter is considered non representative of a problem for the patient, to 4 , in which nasal obstruction represents a major problem. The total score was summed and multiplied by 5 so the maximum score is 100 and the least score is 0 .

\section{Operative technique:}

All cases underwent open rhinoplasty. Local infiltration was done 15 minutes before starting the procedure. The domes, middle, and medial crura were divided in the midline. An extra mucosal dissection was conducted from the connecting point of the upper lateral cartilages and the septum in a retrograde fashion. This was done essentially on the concave side where the chance for mucosal perforation is more common.

\section{$1^{\text {st }}$ group the extra corporeal group (ECS):}

After complete nasal septum dissection, the cartilaginous part was bluntly dislodged from its all attachments from the anterior nasal spine, maxillary crest and the bony septum using blunt dissector e.g.: Freer blunt dissector. The bony septum was accessed by removing the bone spikes or removal of the most of it by using small gouge.

The cartilaginous part was then carefully examined to detect the deviation; structural integrity and sites of previous trauma. Three grafts were harvested from the cartilaginous septum to create two spreader grafts \& one columellar strut. An Lshaped strut was preserved dorsally and caudally. 
Spreader grafts design of 2-4ml width and 1$2 \mathrm{ml}$ thickness extending to the caudal edge then secured to the septum using 5/0 polypropylene in a fashion of transverse mattress suture (Fig. 1). One case the costal cartilage was used as a source of spreader grafts due to deficiency of the remaining septum from the previous operation.

Also, in other case with CT revealing large bone spur at the osteo-cartilagenous junction; enbloc dissection of the whole septum after hump reduction and rasping of this spur was done (Fig. 2 ). Then procedure was proceeded with same sequence in all cases.

After completion of our modification, correction of the septum and securing the spreader grafts the septum was then placed between the upper lateral cartilages. A 4/0 polypropylene was used in a fashion of transverse mattress suture traversing the upper lateral cartilages, the spreader on both sides and the septum in a single knot.

Extreme caution was addressed to close any dead space between the two mucoperichondeal flaps over the septum using sewing suture with 4/0 absorbable suture e.g.: Vicryl; although of the internal splinting of the septum.

\section{$2^{\text {nd }}$ group Insitu septoplasty (ISS):}

15 patients underwent open septoplasty preserving the attachments of the septum. L-shape strut with at least $1 \mathrm{~cm}$ width dorsally and caudally at was preserved with its normal attachments. Two spreader grafts of about 1-2ml thickness and 2-4 $\mathrm{ml}$ width were used to reconstruct the internal nasal valve angles on both sides.

The bony septum was approached in all of cases by removing the bony spurs; only in 3 cases the whole bony part was removed by beveled gouge. Then spreader grafts were fixed by using transverse mattress suture traversing the upper lateral, cartilages the spreader grafts on both side and the septum in between.

In both groups; other standard steps regarding other components of rhinoplasty procedure were taken. SMAS flaps were closed over the dorsum to conceal for any irregularities closed using 4/0 Vicryl. Then the incisions were closed in a classic fashion.

External and internal nasal splints were used plus the internal nasal packing. Nasal packing was removed 72 hours post-operatively in the first group and after 24 hours in the second group.
First follow-up visit was after 5 days for stitch removal and re-dressing of the external splint then after 2 weeks for removal the external and the internal nasal splints. After that photos were taken early in the postoperative period (for patient assurance) then 6 months post-operatively. NOSE scale was used to detect the improvement 6 months after surgery by the same detector preoperatively. Any postoperative complication was managed accordingly.

\section{Statistical analysis:}

IBM's SPSS statistics (Statistical Package for the Social Sciences) for windows (version 25, 2017) was utilized for statistical analysis of the gathered data.

\section{Auxiliary procedures:}

Inferior turbinectomy was done as an auxiliary procedure for cases with persistent symptoms.

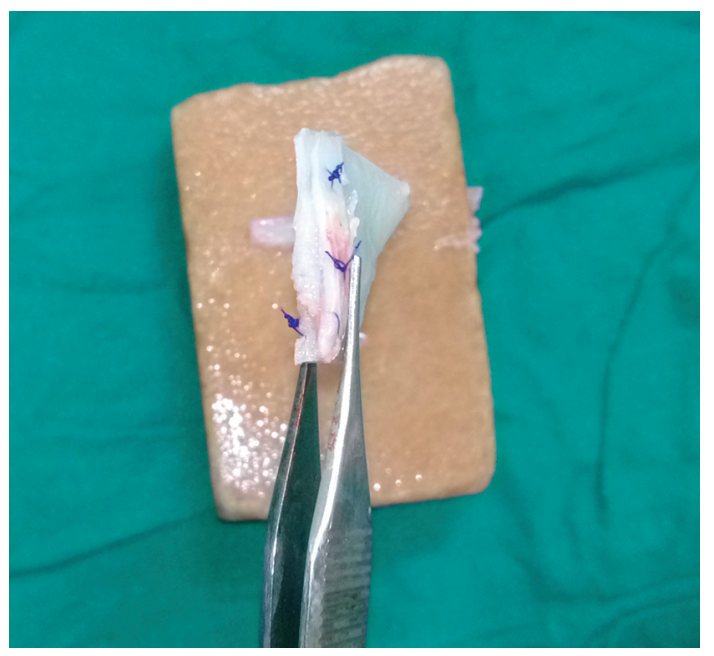

Fig. (1): Spreader grafts anchored to the septum using polypropylene $5 / 0$ transverse mattress suture.

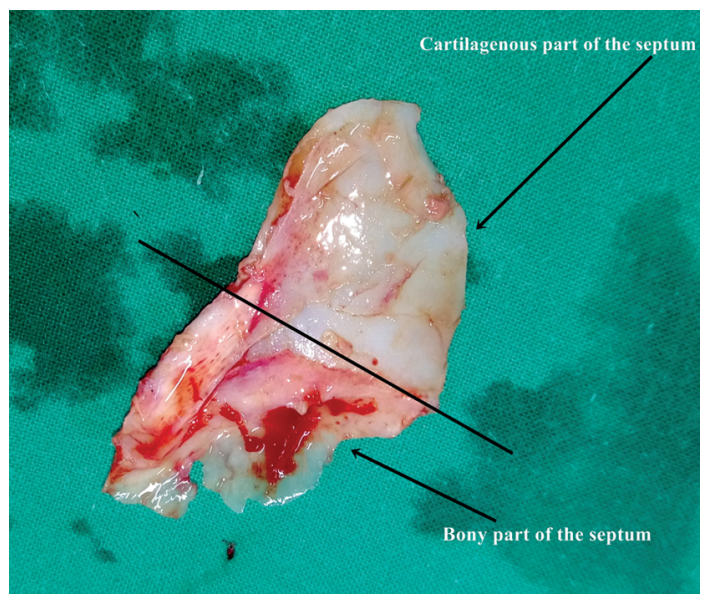

Fig. (2): Showing the en-bloc septal exteriorization of both the bony and the cartilaginous parts. 

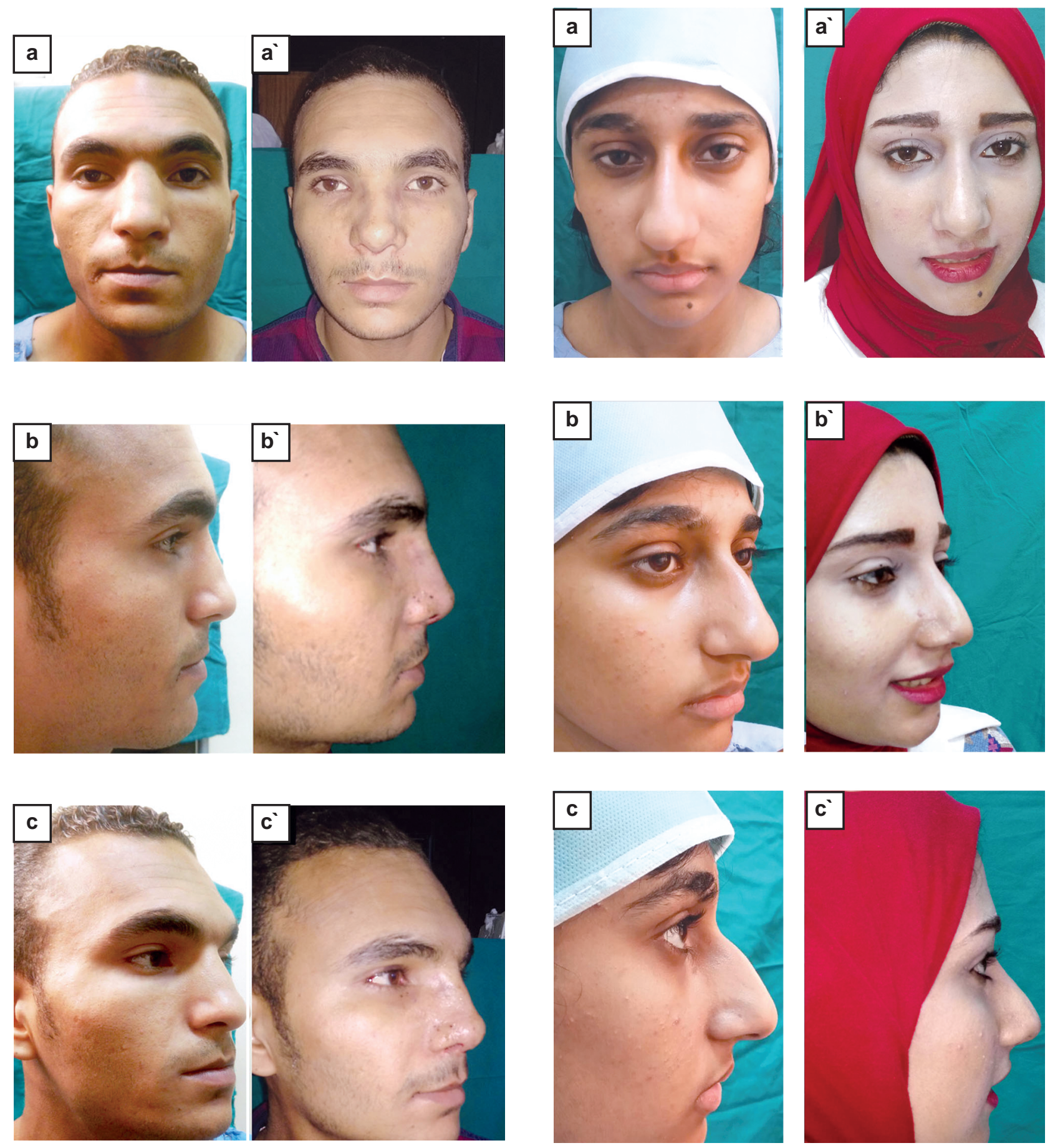

Fig. (3): An example of one of the cases of the extracorporeal septorhinoplaty group for a male patient 29 years in frontal, lateral and oblique views. a, b, c represent the preoperative views. a', b', c` represent the postoperative views.

Fig. (4): An example of one of the cases of the extracorporeal septorhinoplaty group for a female patient 20 years in frontal, lateral and oblique views. a, b, c represent the preoperative views. $a^{\prime}, b^{\prime}, c^{`}$ represent the postoperative views. 

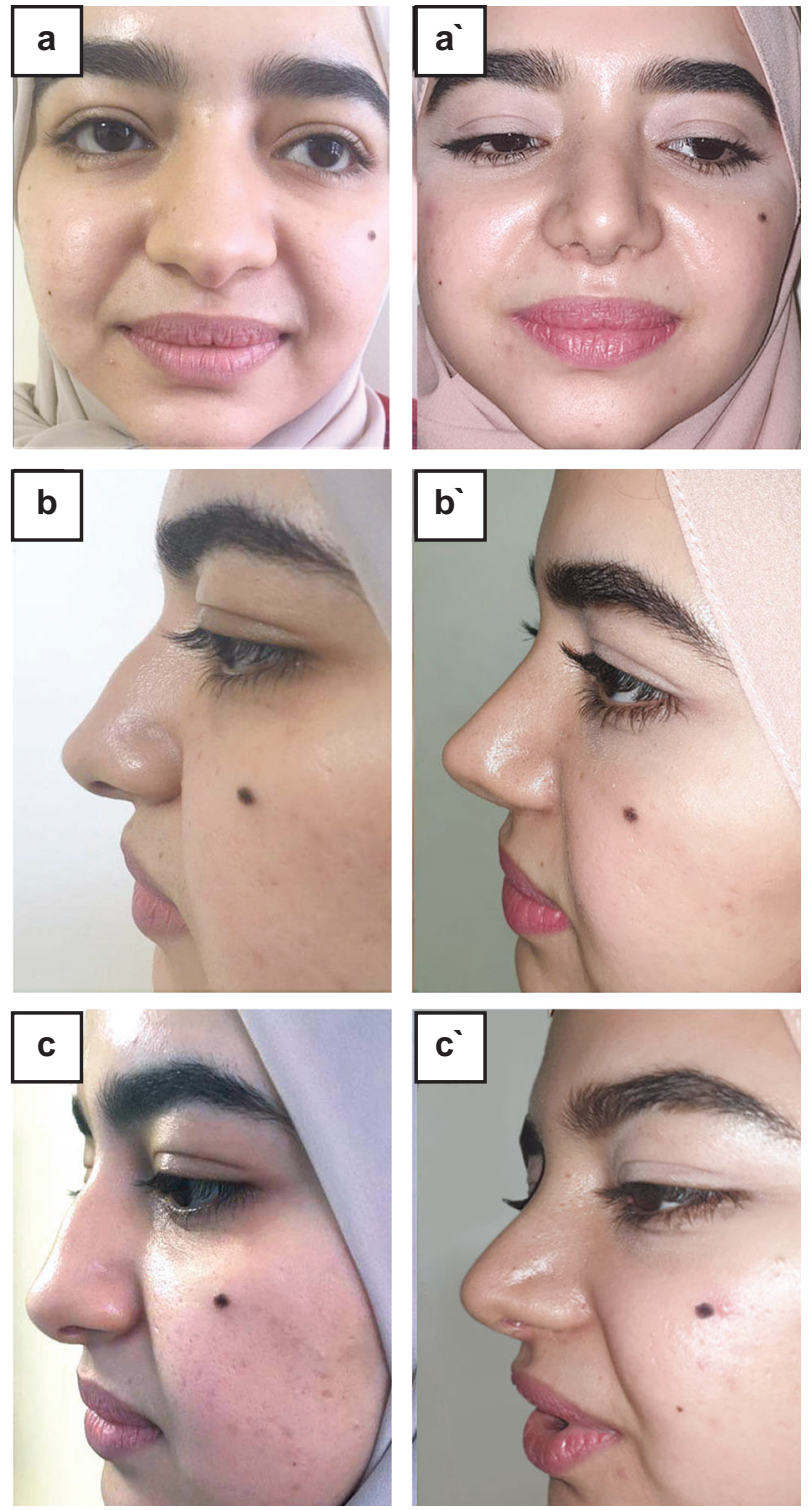

Fig. (5): An example of one of the cases of Insitue septorhinoplaty group for a female patient 24 years in frontal, lateral and oblique views. a, b, c represent the preoperative views. $a^{\prime}, b^{\prime}, c^{\prime}$ represent the postoperative views.

\section{RESULTS}

In our study the mean age of the extracorporeal group was about $24.93 \pm 6.017$ years old years, compared to $28.27 \pm 3.195$ years in the Insitu group. There were 6 males and 9 females in the extracorporeal group. The Insitu group involved 3 males and 12 females.

In this study, the average operative time in the extracorporeal group was $120.33 \pm 20.569$ minutes. While, it was significantly less in the Insitu group with an average of $105.33 \pm 10.933$ minutes.

A repeated measure ANOVA test was conducted to compare the NOSE score between the two groups. NOSE score was measured as basal level before the surgery and six months post-operatively. NOSE score improved in both group after conducting either procedures. Table (1).

The mean duration of the nasal packing in the extracorporeal group was (73.2 hours) which was significantly higher than that of the Insitu group (23.2 hours). On the other hand, as regards the patient satisfaction, it showed higher percentages in the Insitu group than the extra corporeal group after two weeks. Whereas after six months there was no statistical difference (Table 2).

Fortunately, no cases of nose saddling, septal perforation, dorsal irregularities, septal hematoma, postoperative infection persistent bleeding or bilateral nasal obstruction were reported in our study in both groups. However, unilateral persistent obstruction was reported in two cases and one case in the extracorporeal and Insitu groups respectively (Table 3).

Table (1): Basal and post-operative NOSE score of both groups.

\begin{tabular}{lclll}
\hline $\begin{array}{l}\text { NOSE } \\
\text { score }\end{array}$ & $\begin{array}{c}\text { Extracorporeal } \\
\text { group } \\
(\mathrm{n}=15)\end{array}$ & $\begin{array}{c}\text { In-situ } \\
\text { group } \\
(\mathrm{n}=15)\end{array}$ & $95 \% \mathrm{CI}$ & $\begin{array}{c}p \text { - } \\
\text { value }\end{array}$ \\
\hline Basal & $58.33 \pm 7.480$ & $61.00 \pm 6.866$ & $-8.04,2.7$ & 0.32 \\
6 months & $6.33 \pm 7.148$ & $6.00 \pm 3.381$ & $-2.25,2.91$ & 0.79 \\
\hline
\end{tabular}

- Data is expressed as mean and standard deviation. 95\% CI: 95\% confidence interval of the mean difference between both groups. $p$ is significant when $<0.05$. Bonferroni adjustment for multiple comparisons was applied.

Table (2): Duration of nasal packing and patient satisfaction.

\begin{tabular}{lcccc}
\hline & $\begin{array}{c}\text { Extracorporeal } \\
\text { group } \\
(\mathrm{n}=15)\end{array}$ & $\begin{array}{c}\text { In-situ } \\
\text { group } \\
(\mathrm{n}=15)\end{array}$ & $95 \%$ CI & $\begin{array}{c}p- \\
\text { value }\end{array}$ \\
\hline $\begin{array}{l}\text { Nasal packing } \\
\text { (hours) }\end{array}$ & $73.2 \pm 6.085$ & $23.20 \pm 5.003$ & $45.8,54.2$ & $<0.001$ \\
$\begin{array}{l}\text { Patient } \\
\text { satisfaction: }\end{array}$ & & & & \\
$\quad 2$ weeks & $33 \%(5)$ & $60 \%(9)$ & $-0.08,0.61$ & 0.27 \\
6 months & $73 \%(11)$ & $87 \%(13)$ & $-0.15,0.42$ & 0.33 \\
\hline
\end{tabular}

Table (3): Post-operative patient complications in both groups.

\begin{tabular}{lcccc}
\hline Complications & $\begin{array}{c}\text { Extracorporeal } \\
\text { group } \\
(\mathrm{n}=15)\end{array}$ & $\begin{array}{c}\text { In-situ } \\
\text { group } \\
(\mathrm{n}=15)\end{array}$ & $95 \% \mathrm{CI}$ & $\begin{array}{c}p- \\
\text { value }\end{array}$ \\
\hline Nose saddling & $0 \%(0)$ & $0 \%(0)$ & - & 1 \\
Septal perforation & $0 \%(0)$ & $0 \%(0)$ & - & 1 \\
Dorsal irregularities & $0 \%(0)$ & $0 \%(0)$ & - & 1 \\
Septal hematoma & $0 \%(0)$ & $0 \%(0)$ & - & 1 \\
Postoperative infection & $0 \%(0)$ & $0 \%(0)$ & - & 1 \\
Persistent bleeding & $0 \%(0)$ & $0 \%(0)$ & - & 1 \\
Unilateral persistent & $13.3 \%(2)$ & $6.7 \%(1)$ & - & 0.543 \\
$\quad$ obstruction & & & $0.28,0.15$ & 1 \\
Bilateral persistent & $0 \%(0)$ & $0 \%(0)$ & - & 1 \\
$\quad$ obstruction & & & & \\
\hline
\end{tabular}

- Data is expressed as mean and standard deviation or percentage and frequency. $95 \%$ CI: $95 \%$ confidence interval of the mean difference between both groups. $p$ is significant when $<0.05$. 


\section{DISCUSSION}

Rhinoplasty is a common aesthetic procedure that has been carried out for a long period of time and has become popular all over the world. Rhinoplasty represents a great percentage of procedures in the field of facial aesthetic surgery [19].

Septal deviation is the commonest etiology of nasal obstruction which makes septoplasty one of the most frequently conducted techniques in facial plastic surgery [20].

In extreme septal deformities, it is difficult to address the septum by traditional endonasal or open approaches, and therefore the extracorporeal procedures may be more appropriate. Extracorporeal septoplasty (ECS) is very useful in such cases as, without building a new septum, the deformity is difficult to be corrected through surgical procedures with conventional methods or will frequently return postoperatively [21].

Although extracorporeal septoplasty alone may be inadequate to correct a difficult nasal septum as the deformed septal cartilage has to be segmented into multiple smaller sections. It is not only technically complex but also time consuming as it is difficult to stitch the quadrangular septal cartilage from end to end. In addition, this procedure can induce overlapping of the cartilaginous parts causing thickening of the nasal septum [22].

Middle third is the fulcrum of the nose that is composed of nasal bone, septal cartilage, and upper lateral cartilages. Nasal hump resection and dorsum correction can induce change the integrity of that triad structure and without adequate reconstruction of this region; nasal deformity and collapse of the internal nasal valve can occur. Spreader grafts are described as one of the supportive elements in middle vault reconstruction [23].

Hence, the current study was conducted to compare the surgical outcomes of extracorporeal septoplasty with traditional Insitu septal correction in the management of a deviated nose. In both groups; spreader grafts were used to reconstruct the internal valve area.

The current study is composed of two groups of patients namely the Extracorporeal group $(n=15)$ and the Insitu group $(n=15)$. The demographic data of the included cases in the study showed that there was no statistically significant change among both studied groups as regards the age or gender.

Regarding the operative duration (starting from the time of incision till external splint placement), the mean Extracorporeal technique duration was statistically significant longer compared to the Insitu technique. Extracorporeal septoplasty took approximately 15 minutes longer than Insitu septal correction.

This extra time was attributed to the time needed to perform dissection of the septum completely outside the body, the modification of the septum and placement of the spreader graft outside the body, then the reinsertion and fixation of the septum in its proper position.

A cohort of 1753 patients who underwent plastic surgical techniques demonstrated that duration of surgery is considered as an independent predictor for the complications with a significantly increased risk after three hours [24].

Lee and Jang compared the two approaches in their retrospective research and revealed that the mean operation time of extracorporeal septoplasty was around seven minutes longer than ISSC. This is similar to our study with longer time may be due to preparation of the spreader grafts. On the other hand; they reported that extracorporeal septoplasty was better particularly in terms of functional outcomes compared to Insitu technique. This study has its limitations according to the authors principally from the retrospective design and the absence of postoperative objective functional outcome measurements [25].

The current study has compared the functional outcomes of extracorporeal septoplasty with those of Insitu septal correction. However, after the surgery there was a statistically significant difference among both studied groups regarding the mean post-operative nasal packing time which was 23.20 hours for the Insitu septal correction compared with 73.2 hours for the extracorporeal septoplasty. Generally, the patient satisfaction postoperative 2 weeks and 6 months was comparable between the extracorporeal septoplasty and ISSCs groups. (Figs. 3,4) show an example of the extracorporeal group with preoperative NOSE score of 55,45 and postoperative score of 5,10 respectively. (Fig. 5) shows an example of the Insitu with preoperative score of 60 and postoperative score of 5 .

For functional assessment; validated NOSE score was used to determine the degree of improvement before and after six months of the operation. In the extracorporeal septoplasty group, there was a statistically significant difference between the basal and 6 months post-operative NOSE score of 58.33 versus 6.33 respectively. 
This indicated a significant improvement in the functional outcomes of extracorporeal septoplasty. On the other hand, the Insitu septal correction technique showed greater significant difference between the basal and 6 months post-operative score of 61.00 versus 6.00 respectively; indicating much more improvement among the ISSCs patients. However, when comparing the two groups, there was no statistically significant difference regarding the scores.

Therefore and according to the results of the present study, deviated septum can be corrected effectively by either extracorporeal septoplasty or Insitu septal correction. The latter yielded better results than extracorporeal septoplasty in terms of NOSE score. However, such difference did not reach a statistically significant level. These results may be attributed to internal valve reconstruction by spreader grafts rather than the technique used in septal correction.

Gubisch reviewed the outcomes of 2119 patients who underwent extracorporeal septoplasty for markedly deviated septum. The whole septum is removed and reshaped in extracorporeal septoplasty, while the integrity of the structures is preserved in Insitu technique [26].

Consistent with the current study results, Gode et al., reported that there was no statistically significant difference in the nasal scores between extracorporeal septoplasty and Insitu groups [27].

Most reported different results. According to authors, extracorporeal septoplasty can be used effectively compared with Insitu septoplasty when there were much worse preoperative nasal criteria or score $[28,29]$.

Spreader grafts may play the role in this difference of the results. Our results showed that mean pre-operative (basal) NOSE score was higher among Insitu septoplasty patients (61.00) compared with extracorporeal septoplasty patients (58.33) and that the Insitu septal correction yielded much better mean post-operative score (although not statistically significant) than the extracorporeal septoplasty indicating that Insitu septoplasty can be used effectively in patients with high NOSE score deviated noses compared with extracorporeal septoplasty. This is provided we reconstruct the internal valve area with spreader graft.

This study shows that, there is no precise indication for extracorporeal septoplasty or Insitu septal correction since it is not a subject of this study. Internal valve reconstruction plays very important role in functional outcome.

Limitations of this study were low patient numbers, short term follow-up and absence of objective evaluation tools like the radiologic or rhinometeric evaluation. Further randomized researches with different patient groups for all techniques are required to explain the possible objective indications.

As regard complications, there were no significant complications to report. The same incidence of complications have been reported in similar studies including; Karamese et al., There were only 3 cases of unilateral persistent obstruction due to inferior turbinate hypertrophy that was corrected by doing turbinectomy [30].

\section{Conclusion:}

The Extracorporeal septoplasty and ISS techniques with internal valve reconstruction have a comparative efficacy in the improvement of functional and aesthetic outcomes of patients undergoing septoplasty. However, Insitu septoplasty may be slightly better due to less operative time and the more conservative dissection.

\section{REFERENCES}

1- Barıs Cakır, Teoman Doğan, Ali Rıza Oreroğlu and Rollin K. Daniel: Rhinoplasty: Surface Aesthetics and Surgical Techniques. Aesthetic Surgery Journal, 33: 363-375, 2013.

2- https://www.plasticsurgery.org/documents/News/ Statistics/2018/plastic-surgery-statistics-full-report-2018.pdf. Page 7 Accessed June 20, 2019.

3- Heppt W. and Gubisch W.: Septal surgery in rhinoplasty. Facial Plastic Surgery, 27: 167-178, 2011.

4- Yiqiao Wang and James P. Bonaparte: Diagnosis and management of septal deviation and nasal valve collapsea survey of Canadian otolaryngologists Journal of Otolaryngology - Head and Neck Surgery, 48: 71, 2019.

5- Cho G.S. and Jang Y.J.: Deviated nose correction: Different outcomes according to the deviation type, The Laryngoscope, 123 (5): 1136-1142, 2013.

6- Artur Gevorgyan and Oakley Smith: Correcting a Bent Septum by a K-Wire Stabilization During an Extracorporeal Septal Reconstruction. Aesth. Plast. Surg., 37: 698703, 2013.

7- Persichetti P., Toto V., Marangi G.F. and Poccia I.: Modified Extracorporeal Septoplasty: Functional, Results at 6 years follow-up. Head and Neck Surgery, 5: 504-508, 2016.

8- Song H.M., Kim J.S., Lee B.J. and Jang Y.J.: Deviated nose cartilaginous dorsum correction using a dorsal Lstrut cutting and suture technique. The Laryngoscope, 6 : 1-986, 2008.

9- Kim J.H., Kim D.Y. and Jang Y.J.: Outcomes after endonasal septoplasty using caudal septal batten grafting. American Journal of Rhinology \& Allergy, 4166-1, 2011. 
10- King E.D. and Ashley F.L.: The correction of the internally and externally deviated nose. Plast. Reconstr. Surg., 10 (2): 116-120, 1952.

11- Gubisch W.: Extracorporeal septoplasty for the markedly deviated septum. Arch. Facial Plastic Surgery, 7: 218226, 2005.

12- Persichetti P., Toto V., Marangi G.F., et al.: Extracorporeal septoplasty: Functional results of a modified technique. Annals of Plastic Surg., 69: 232-239, 2012.

13- Gubisch W.: Twenty-five years experience with extracorporeal septoplasty. Facial Plastic Surgery, 2: 230-239, 2006.

14- Tasca I., Ceroni Compadretti G. and Sorace F.: Nasal valve surgery. Acta. Otorhinolaryngolica Italica, 33: 196201, 2013.

15- Wittkopf M., Wittkopf J. and Ries W.R.: The diagnosis and treatment of nasal valve collapse. Curr. Opin. Otolaryngol. Head Neck Surg., 16 (1): 10-3, 2008.

16- Fischer H. and Gubisch W.: Nasal valves-importance and surgical procedures. Facial Plastic Surgery, 22: 266-280, 2006.

17- Kohsh M.M., Jen A., Honrado C., et al.: Nasal valve reconstruction: Experience in 53 consecutive patients. Arch. Facial Plastic Surgery, 6: 167-171, 2004.

18- Stewart M.G., Wit Sell D.L. and Smith T.L.: Development and validation of the Nasal Obstruction Symptom Evaluation (NOSE) Scale. Otolaryngology-Head and Neck Surgery, 130: 157-163, 2004.

19- Thomas Yu Xia, Ayesha Punjabi, Jessica Hyejin Oh, Corinne Wee and Bahman Guyuron: Updated Dynamics of Rhinoplasty: A Review of the Literature and Comprehensive List of the Findings. Aesth. Plast. Surg., 2020.

20- Sam P. Most and Shannon F. Rudy: Septoplasty Basic and Advanced Techniques. Facial Plast. Surg. Clin. N. Am., 1-9, 2017.

21- Matt A. Wilson and Steven R. Mobley: Extracorporeal
Septoplasty Complications and New Techniques. Arch. Facial Plast. Surg., (13): 85-90, 2011.

22- L. Somu, Prasanna Kumar Saravanam, A. Ravi Kumar, Urvashi S., Prem Nivas, Gokul An and M.S.: Extracorporeal Septoplasty Using Polydioxanone Plates v/s. Conventional Septoplasty in Management of Difficult Septum. Evolution of Medical and Dental Sciences, 4 (73): 1274212753, 2015.

23- Omer Faruk Kocak and Ufuk Düzenli: Assessment of Vertical Triangular Spreader Graft Technique for Reconstruction of Middle Vault and Internal Nasal Valve Angle.The Journal of Craniofacial Surgery, 29: 2096-2100, 2018.

24- Hardy K.L., Davis K.E., Constantine R.S., et al.: The impact of operative time on complications after plastic surgery: A multivariate regression analysis of 1753 cases. Aesthet. Surg. J., 34: 614-22, 2014.

25- Lee S.B. and Jang Y.J.: Treatment Outcomes of Extracorporeal Septoplasty Compared With In Situ Septal Correction in Rhinoplasty. JAMA Facial Plast. Sur., 16 (5): 328334, 2014.

26- Gubisch W.: The extracorporeal septum plasty: A technique to correct difficult nasal deformities. Plast. Reconstr. Surg., 95: 672-682, 1995.

27- Gode S., Benzer M., Uslu M., et al.: Outcome of In Situ Septoplasty and Extracorporeal Subtotal Septal Reconstruction in Crooked Noses: A Randomized Self-Controlled Study. Aesth. Plast. Surg., 42: 234-243, 2018.

28- Senyuva C., Yucel A., Aydin Y., Okur I. and Guzel Z.: Extracorporeal septoplasty combined with open rhinoplasty. Aesthetic Plast. Surg., 21: 233-239, 1997.

29. D'Andrea F., Brongo S. and Rubino C.: Extracorporeal septoplasty with paramarginal incision. Scand J. Plast. Reconstr. Surg. Hand Surg., 35: 293-296, 2001.

30- Karamese M., Akda O., Akatekin A., Koplay T.G., Koplay M. and Tosun Z.: Extracorporeal Septoplasty Combined With Valve Surgery in Rhinoplasty Patients. Annals of Plastic Surgery, 12: 1-7, 2017. 